African Crop Science Journal by African Crop Science Society is licensed under a Creative Commons Attribution 3.0 Uganda License. Based on a work at www.ajol.info/ and www.bioline.org.br/cs DOI: http://dx.doi.org/10.4314/acsj.v24i1.8

\title{
SIMPLE SEQUENCE REPEAT MARKERS ASSOCIATED WITH ANTHRACNOSE AND Turcicum LEAF BLIGHT RESISTANCE IN SORGHUM
}

\author{
M.M. BESHIR ${ }^{1,2}$, A.M. ALI ${ }^{2,3}$, P. RUBAIHAYO ${ }^{1}$, N.E. AHMED ${ }^{4}$ and P. OKORI ${ }^{1}$ \\ ${ }^{1}$ Department of Agricultural Production, Makerere University, P. O. Box 7062, Kampala, Uganda \\ ${ }^{2}$ Biotechnology and Biosafety Research Centre, Agricultural Research Corporation, P. O. Box 30, \\ Shambat, Sudan \\ ${ }^{3}$ Plant Breeding and Genetics Laboratory, FAO/IAEA Joint Division of NA, International Atomic Energy \\ Agency Laboratories, Seibersdorf, Austria \\ ${ }^{4}$ Crop Protection Centre, Agricultural Research Corporation, P. O. Box 126, Wad Medani, Sudan \\ Corresponding authors: p.okori@cgiar.org, patrick.okori@yahoo.com, mayadabeshir2015@gmail.com
}

(Received 24 August, 2015; accepted 20 February, 2016)

\begin{abstract}
Deployment of host resistance remains the most cost effective strategy for management of foliar and grain diseases, especially for resource constrained farmers. There is paucity of information on dual resistance in sorghum to both diseases. The objective of this study was to identify SSR markers associated with anthracnose and TLB resistance in sorghum for future use in markers assisted introgression. Mapping of resistance to anthracnose and Turcicum leaf blight (TLB) was undertaken in $126 \mathrm{~F}_{8: 9}$ sorghum recombinant inbred lines, derived from a cross between MUC007/009 and Epuripuri. The $\mathrm{F}_{8.9}$ RILs were evaluated for field resistance to anthracnose and TLB in Uganda and Sudan. There were significant differences among locations $(\mathrm{P}<0.001)$, suggesting a strong influence of environments on reaction to both diseases. Transgressive segregation was observed, indicating that both parents carried minor loci or alleles for resistance that differed from each other. SSRs Xtxp25, Xtxp201, Xtxp302, Xtxp25, Xtxp295 and Xtxp95 were associated, respectively, with anthracnose and TLB resistance, consistent with dominant epistasis gene action. The SSRs Xtxp201 and Xtxp303 were associated with both anthracnose and TLB resistance. High polymorphic information content (0.44 to 0.59) and gene diversity ( 0.54 to 0.66 ) were observed. SSRs could be used to detect the dual resistant genotypes and, therefore, contribute substantive information to multiple disease resistance research of sorghum.
\end{abstract}

Key Words: Dual resistance, simple sequence repeats

\section{RÉSUMÉ}

Le développement d'hôtes résistantes demeure la plus efficace des stratégies de lutte contre les maladies foliaires et de grains, surtout en direction de petits producteurs à ressources limitées. There is paucity of information on dual resistance in sorghum to both diseases. L'objectif de cette étude était d'identifier des marqueurs SSR associés à la résistance du sorgho à l'anthracnose et la maladie de brulure foliare causée par le Turcicum, dans une perspective d'introgression de gènes assistée par des marqueurs. La cartographie des genes associées à ces maladies a été entreprise avec une population de $126 \mathrm{~F}_{8: 9}$ lignées de sorgho (RILs), obtenues d'un croisement entre derived MUC007/009 et Epuripuri. Les lignées $\mathrm{F}_{8: 9}$ ont été évaluées en Ouganda et au Soudan pour leur résistance à à l' anthracnose et la maladie de brulure foliare causée par le Turcicum. Des différences significatives $(\mathrm{P}<0.001)$ ont été observées entre les locations. Ceci montre que les facteurs environnementaux ont une influence majeure dans la résistance à ces deux maladies. Une ségrégation transgressive a été observée, indiquant que les deux parents sont porteurs de différents loci mineurs ou allèles de résistance. SSRs Xtxp25, Xtxp201, Xtxp302, 
Xtxp25, Xtxp295 et Xtxp95 étaient respectivement associés à la résistance à l'anthracnose et à la maladie de brulure foliare causée par le Turcicum, et ceci de façon consistante avec un effet épistatique des gènes. Les SSRs Xtxp201 et Xtxp303 étaient associés à la résistance aux deux maladies. Une part élevée de polymorphisme (0.44 to 0.59 ), et de diversité de gène (0.54 to 0.66 ) ont été observée. Les marqueurs SSRs pourront donc être utilisés pour détecter des génotypes à double résistance, et par conséquent, contribuer pour une grande part dans la recherche de résistance multiple chez le sorgho.

Mots Clés: Double résistance, répétitions de séquences simples

\section{INTRODUCTION}

Sorghum (Sorghum bicolor) grain production in most sub-Saharan Africa, South East Asia and the Americas is estimated at $32-70 \%$ (Sharma et al., 2007). The total production in 2009 in East Africa was $1,183 \mathrm{~kg} \mathrm{ha}^{-1}$, compared with yields in the United States of America (4354 kg ha ${ }^{-1}$ ) and well below the genetic potential (FAOSTAT, 2011). The low productivity is caused by endemic diseases anthracnose (Colletotrichum sublineolum Ces.) Munt.-Cvetk. (anamorph Colletotrichum graminicola) and Turcicum leaf blight (TLB) (Exserohilum turcicum (Pass) Leonard and Suggs (teliomorph: Setosphaeria turcica (Luttrell) Leonard and Suggs) (Ngugi et al., 2000; Ramathani et al., 2011). In many tropical environments, both diseases are endemic with prevalence of different races of $E$. turcicum and diverse Colletotrichum sublineolum (Ramathani et al., 2011; Sserumaga et al., 2013). Both diseases are polycyclic with similar epidemics (Costa et al., 2011; Ramathani et al., 2011).

Deployment of host resistance remains the most cost effective strategy for management of these foliar and grain diseases, especially for resource constrained farmers. There is paucity of information on dual resistance in sorghum to both diseases (Ngugi et al., 2000). However, studies conducted separately for each disease show that both qualitative and quantitative resistance mechanisms condition resistance (Paterson, 2008; Tesso et al., 2012; Rajeshwar et al., 2014). Deployment of quantitative resistance for management of both diseases will invariably reduce pressure for evolution of new pathogen races (McDonald and Linde, 2002; Okori et al., 2015). However breeding for quantitative resistance is challenged with uneven disease pressure and or erratic epidemics, especially under natural field conditions.

The use of molecular markers has been suggested as a better approach to breed for such complex traits. Mohan et al. (2009) show that markers linked to resistance loci can improve precision in selection for resistance loci when resistance loci has been mapped and associated molecular markers. The roles of specific resistance loci and race-specificity of partial resistance loci can be accessed by mapping the quantitative trait loci (QTL) (Mittal and Boora, 2005). Paterson (2008) reported that interactions between resistance loci and plant development can as well be identified using QTL.

In different crop species, QTL associated with disease resistance have been mapped and are being introgressed using line conversion breeding strategies such as backcross breeding (Varshney et al., 2014). In sorghum, molecular markers have been used successfully for isolation of loci for resistance to target leaf spot, zonate leaf spot and drechslera leaf blight (Mohan et al., 2009). While in maize, molecular markers have also used successfully for isolation of loci for resistance to TLB, grey leaf spot and southern leaf blight in maize (Ali et al., 2013). Given that both diseases are endemic in many tropical countries and indeed germplasm for each disease separately observed, the presence of dual resistance to both diseases cannot be precluded. Presence of and the co-localisation of QTL that confer resistance to anthracnose and TLB are desirable; and the identification of molecular markers linked to them could improve breeding for resistance. The aim this study was to identify SSR markers associated with anthracnose and TLB resistance in sorghum for future use in markers assisted introgression. 


\section{MATERIALS AND METHODS}

Experimental sites. Molecular characterisation of $\mathrm{F}_{8.9}$ sorghum population was carried out at the Biotechnology and Biosafety Research Centre, Agricultural Research Corporation (ARC) in Sudan. Phenotypic characterisation was done under field conditions at Makerere University Agricultural Research Institute, Kabanyolo (MUARIK), the National Semi-Arid Resources Research Institute (NaSARRI) in Uganda, and at Gezira Research Station of ARC at Wad Medani and Wad Elturabi in Sudan. All these locations are hotspots for both anthranose and TLB (Ramathani et al., 2011; Beshir et al., 2015).

\section{Phenotypic characterisation}

Development of the recombinant inbred lines. One hundred and twenty six $\mathrm{F}_{8: 9}$ recombinant inbred lines (RILs) were developed from a cross of MUC007/009 (a Ugandan accession and source of resistance to TLB, but susceptible to anthracnose), and Epuripuri (a commercial variety and source of resistance to anthracnose, but susceptible to TLB). The $\mathrm{F}_{8.9}$ lines were planted using an alpha lattice design, with three replications in all locations.

Field techniques for inoculation and disease evaluation. On average, 20 to 25 infested air-dried sorghum kernels, containing $C$. sublineolum and E. turcicum inoculum, were placed into the leaf whorls (Ramathani, 2009) at vegetative growth stage two (five leaf stage) (Vanderlip, 1993). Artificial inoculation was used at MUARIK and NaSARRI; while materials were subjected to natural infestation in Wad Medani and Wad Elturabi, using the infector rows of Epuripuri and MUC007/009 suseptible varieties planted two weeks before establishing the experiment.

Phenotypic data evaluation. Disease severities were assessed at weekly intervals, starting two weeks after innoculation, until physiological maturity, based on the scale described by Ramathani (2009). Areas under disease progress curves (AUDPC) were computed using the weekly ratings (Madden et al., 2007).
Data were also taken on lesion type (Beshir, 2011). MUC007/009 and Epuripuri had distinctly different lesion types from each other (Beshir, 2011); MUC007/009 had narrow lesions with a red border and Epuripuri had wider lesions without a red border.

The frequency of the resistant lesion type and the susceptible lesion type was assessed among the 126 RILs. Plot means were calculated and used for the statistical analysis of the field data. Means were computed and subjected to analysis of variance using GenStat $12^{\text {th }}$ Version (VSN International Ltd., UK) (Steel and Torrie, 1997).

\section{Genotypic data characterisation and analysis}

SSR selection. DNA was isolated from two week old leaf tissues of the plants (Edwards et al., 1991). Fifty eight SSRs, from the consensus genetic map of sorghum obtained through Diversity Array Technology (DArT) was used (Mace et al. (2009). These SSRs were synthesized at the Department of Molecular and Cellular Biology, University of Cape Town, South Africa. All SSRs were screened for polymorphism between the parental lines. Twelve of the 58 SSRs were polymorphic between the two parents, representing $21 \%$ of the tested SSRs. Only 7 SSRs, i.e. Xtxp302, Xtxp25, Xtxp201, Xtxp177, Xtxp303, Xtxp295 and Xtxp95, had clearly distinguishable bands on agarose gels and were therefore used for further genetic analysis. These seven SSRs were polymorphic between Epuripuri and MUC007/009. PCR amplification was performed as described by Beshir (2011). For each SSR, the polymorphic information content (PIC) values were used to calculate the genetic diversity according to the formula:

$\mathrm{PIC}=1-\sum_{i=1}^{k} x i^{2}$

Where:

$\mathrm{k}$ is the total number of alleles detected for an SSR and $x i$ is the frequency of the $\mathrm{i}^{\text {th }}$ allele of the SSR loci (Abu Assar et al., 2005).

Genotypic scoring. A qualitative scheme was used to score for presence or absence of 
resistance alleles in homozygous or heterozygous state in the progeny. Recombination inbred lines carrying the susceptibility alleles at the polymorphic SSR loci, were given a zero score; while those carrying the resistant allele were given score of 1 . Segregating progeny carrying alleles from both parents (heterozygote) were given a score of 2 .

Data analysis. The relationship between molecular markers and phenotypic scores was assayed using single marker analysis to identify SSR that were significantly associated with anthracnose and TLB symptoms like lesion type and severity scores. Chi square $\left(\chi^{2}\right)$ was used to test the goodness of fit of observed resistance segregation patterns for anthracnose and TLB to expected segregation ratios among RILs genotypic data at $\mathrm{P}<0.05$.

Analysis of variance and regression analysis were used to detect the significance of the three allelic groups of each SSR (Steel and Torrie, 1997). The allelic groups of RILs, which carried the allele from Epuripuri (the source of resistance to anthracnose), were scored as 0 , those carrying the allele from the MUC007/009 (the source of resistance to TLB) were given a genotypic score as 1 , and those carrying alleles from both parents (heterozygote) were given a genotypic score as 2. All data were analysed using GenStat $12^{\text {th }}$ Version (VSN International Ltd., UK) (Steel and Torrie, 1997). Polymorphic SSRs were located in linkage groups 1, 2, 4, 5, 6 and 7 based on the sorghum map reported by Mace et al. (2009).

\section{RESULTS}

Reaction to anthracnose and TLB. Frequency distributions of the final severity of anthracnose and TLB, AUDPC and lesion type of 126 RILs are presented in Figure 1. Segregation patterns for anthracnose were discontinuous, with evidence of transgressive segregation for resistance to the disease (Fig. 1a and b). AUDPC for anthracnose, a product of integration of the epidemics, was similar to final lesion severity ratings except that most progeny were moderately to highly resistant (Fig.1b).

Turcicum leaf blight was also discontinuous, but less skewered than for anthracnose (Fig. 1c).
AUDPC for TLB, exhibited continuous variation, although slightly skewed for resistance (Fig. 1c). There was no strong evidence of transgressive segregation against the resistant parent MUC007/009 background. The lesion type, i.e. wild type- and non-wild type-tan with reddish halo around each lesion, had one main peak for the number of individual RILs belonging to the class having a score of 1.6 to 2.0. This class had a mixture of tan to reddish lesions (Fig. 1E).

Analysis of variances of AUDPC, final severity ratings for anthracnose and TLB and AUDPC, as well as lesion type are presented in Table 1. No significant differences $(P>0.05)$ were observed among RILs for final severity ratings and AUDPC of both diseases. However, highly significant differences among RILs $(\mathrm{P}<0.01)$, were observed for lesion colour. There was a significant $(\mathrm{P}<0.001)$ effect of environment on the development of both TLB and anthracnose but not for lesion colour.

Segregation of polymorphic SSR. Polymorphic bands, total bands, major allele frequency and PIC frequencies per primer pairs are presented in Table 2. Seven SSRs pairs yielded 1, 046 alleles, and total number of alleles per marker varied between 159 and 132. Primer Xtxp201 had the highest PIC value (0.59), while Xtxp95 had the lowest (0.44). The major allele frequency varied between 0.39 and 0.61 ; and gene diversity ranged between 0.54 and 0.66 .

The distribution of RILs carrying MUC007/ 009, heterozygote and Epuripuri alleles, respectively, among the polymorphic SSRs (Xtxp302, Xtxp25, Xtxp201, Xtxp177, Xtxp303, Xtxp295 and Xtxp95), are presented in Figure 2. The SSRs Xtxp25 and Xtxp95 had the lowest frequency for heterozygote alleles among the RILs, while Xtxp201 had the highest frequency. The SSR Xtxp303 had the highest homozygote allele frequency for Epuripuri (source of resistance to anthracnose but susceptible to TLB), while Xtxp177 had the highest homozygote allele frequency for MUC007/009 (source of resistance to TLB). The genotypic segregation patterns of MUC007/009, Epuripuri and heterozygote alleles showed that resistance to TLB was quantitative (continuous), while resistance to anthracnose was mainly qualitative 

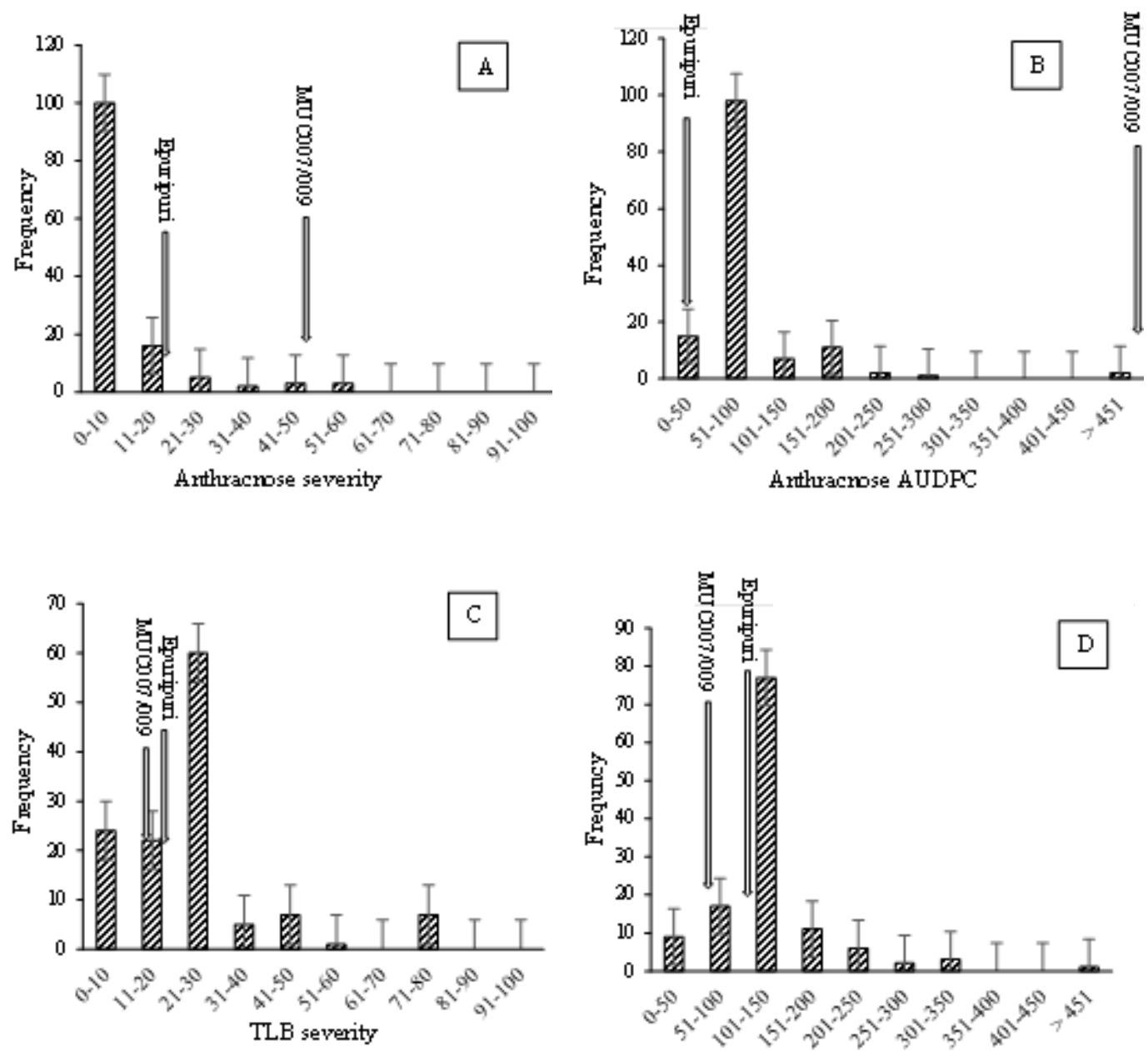

TLB AUDPC

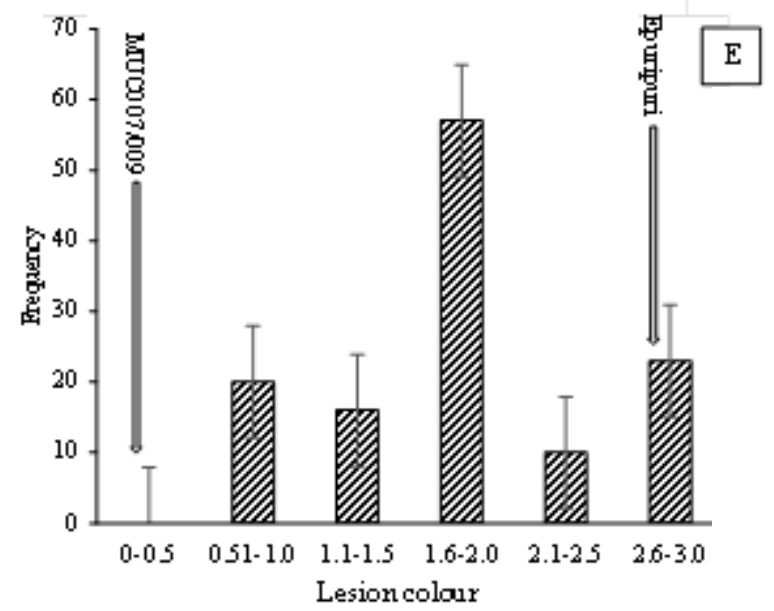

Figure 1. Frequency distribution of mean disease scores in recombinant inbred lines derived from parental lines MUC007/009 and Epuripuri across Uganda and Sudan (rains of 2012 and 2014). Bars show the standard errors ( $\pm S E$ ). $A=$ Anthracnose severity, $\mathrm{B}=$ Anthracnose AUDPC, $\mathrm{C}=$ TLB severity, $\mathrm{D}=$ TLB AUDPC and $\mathrm{E}=$ Lesion colour. 
(discontinuous), similar to what was observed for the phenotypic data.

Single marker analysis. Single marker analysis and segregation pattern for SSR Xtxp302, Xtxp25, Xtxp201, Xtxp177, Xtxp303, Xtxp295 and Xtxp95 are presented in Table 3. There was a highly significant association $(\mathrm{P}<0.01)$ among the SSRs Xtxp201, Xtxp177 and Xtxp303 and anthracnose severity. The SSRs Xtxp25, Xtxp201, Xtxp303, Xtxp295 and Xtxp95 were significantly associated with TLB severity at $(\mathrm{P}<0.1)$. The SSRs Xtxp201 and $\mathrm{Xtxp} 303$ were significantly $(\mathrm{P}<0.05)$ associated with both anthracnose and TLB resistance. Single marker analysis for SSRs Xtxp201 and Xtxp303 showed significant $(\mathrm{P}<0.05)$ association among the allelic groups for anthracnose and TLB severities in the RILs. SSR Xtxp302 showed no association with anthracnose or TLB severity. The goodness of fit of results of the polymorphic SSRs to the expected segregation ratios among RILs genotypic data at $\mathrm{p}<0.05$ using Chi square test are presented in Table 4. Only SSRs Xtxp25 and Xtxp201 had no significant Chi square results, with two loci having a segregation ratio of 9:7, indicative of two loci in epistasis dominant gene action for anthracnose. SSRs Xtxp302, Xtxp25, Xtxp295 and Xtxp95 were not significant with the two loci segregation ratio of 9:7, similarly indicating two loci epistasis dominant gene action for TLB. Other SSRs such as Xtxp177 and Xtxp303 had high significant $(\mathrm{P}<0.001)$ Chi square results implicating more than two loci in dual resistance to TLB and anthracnose. In general, all polymorphic SSRs had no goodness of fit with the genotypic segregation ratios for both diseases.

\section{DISCUSSION}

Reaction to anthracnose and TLB. Analysis of variance revealed that highly significant differences $(\mathrm{P}<0.001)$ among environments, i.e. MUARIK and NaSARRI in Uganda and Wad Medani and Wad Elturabi in Sudan, suggesting that the RILs performed differently and that the environments were effective in reducing experimental errors. However, sensitivity of genotype by environmental interactions are 
TABLE 2. Summary of 7 polymorphic SSRs used to screen 126 RILs

\begin{tabular}{|c|c|c|c|c|c|c|c|}
\hline $\operatorname{RILs}(n=126)$ & Xtxp302 & Xtxp25 & Xtxp201 & Xtxp177 & Xtxp303 & Xtxp95 & Xtxp295 \\
\hline SB Linkage Group ${ }^{\mathrm{a}}$ & 1 & 2 & 2 & 4 & 5 & 6 & 7 \\
\hline No of RILs with MUK007/009 allele & 35 & 62 & 49 & 77 & 31 & 65 & 43 \\
\hline No of RILs with Heterozygote alleles & 29 & 8 & 43 & 18 & 27 & 6 & 33 \\
\hline No of RILs with Epuripuri allele & 62 & 56 & 34 & 31 & 68 & 55 & 50 \\
\hline No of total alleles & 155 & 134 & 169 & 144 & 153 & 132 & 159 \\
\hline Polymorphic information contents & 0.56 & 0.46 & 0.59 & 0.48 & 0.54 & 0.44 & 0.58 \\
\hline Major allele frequency & 0.49 & 0.49 & 0.39 & 0.61 & 0.53 & 0.52 & 0.40 \\
\hline Gene diversity & 0.63 & 0.56 & 0.66 & 0.55 & 0.61 & 0.54 & 0.66 \\
\hline
\end{tabular}

a $=$ Linkage groups were based on the sorghum genome consensus map published by Mace et al., 2009

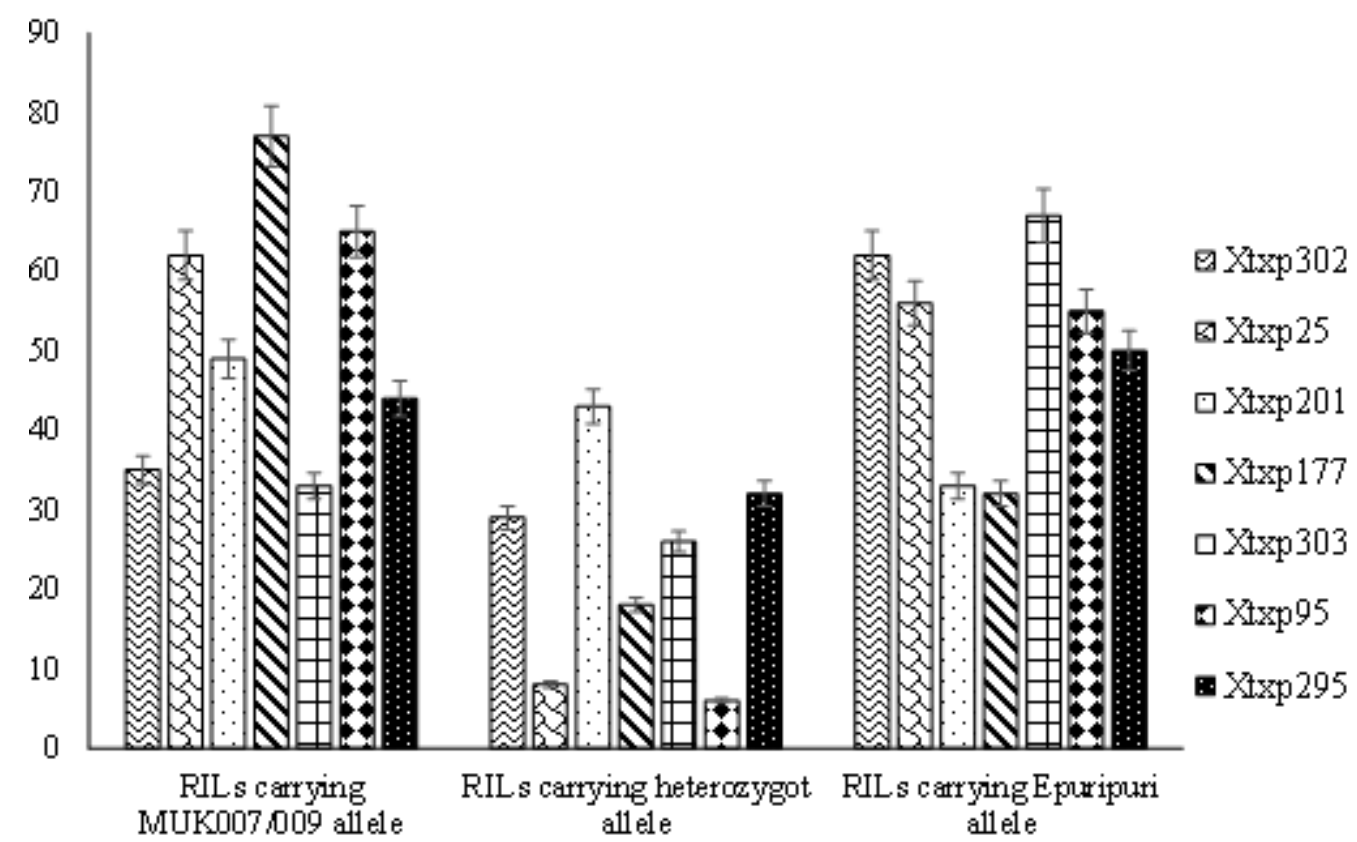

Figure 2. Distribution of frequencies of recombinant inbred lines carrying MUC007/009, heterozygote and Epuripuri alleles, respectively, of the polymorphic SSRs Xtxp302, Xtxp25, Xtxp201, Xtxp177, Xtxp303, Xtxp295 and Xtxp95. Bars show the standard errors $( \pm S E)$ for $S S R s$ markers at $P<0.05$.

common, especially when quantitative inheritance is present (Geiger and Heun, 1989). Analysis of the segregation patterns of RILs provides strong evidence for additive gene action for both diseases with transgressive segregation for resistance to both diseases. Segregation patterns, as shown in the histograms, show that both parents MUC007/009 and Epuripuri carry minor loci or alleles for resistance, different from each other, but that in an additive manner contribute to resistance. This is positive given that selection pressure could be easily deployed to identify novel material with dual resistance to both folia diseases.

The general shape of the histograms confirm resistance to anthracnose as qualitative as previously reported (Costa et al., 2011) and quantitative for TLB (Reddy and Prasad, 2013). Having both qualitative and quantitative gene actions involved, indicated that both disease 
TABLE 3. Mean squares for single marker analysis of the seven polymorphic SSRs among 126 RILs under Uganda and Sudan field conditions (rains of 2012 and 2014)

\begin{tabular}{|c|c|c|c|c|c|c|c|c|}
\hline \multirow{3}{*}{$\begin{array}{l}\text { Source of } \\
\text { variation }\end{array}$} & \multicolumn{4}{|c|}{ Anthracnose } & \multicolumn{4}{|c|}{ Turcicum leaf blight } \\
\hline & \multicolumn{2}{|c|}{$\mathrm{AUDPC}^{\mathrm{a}}$} & \multicolumn{2}{|c|}{ Severity ${ }^{b}$} & \multicolumn{2}{|c|}{ AUDPC $^{a}$} & \multicolumn{2}{|c|}{ Severity ${ }^{b}$} \\
\hline & MS & F test & MS & F test & MS & F test & MS & F test \\
\hline Xtxp302 & 103.0 & 0.1 & 52.4 & 0.6 & 5009.0 & 1.3 & 166.2 & 0.6 \\
\hline Xtxp25 & 215.0 & 0.1 & 71.5 & 0.9 & $19657.0^{* *}$ & $5.3^{* *}$ & 456.1 & 1.8 \\
\hline Xtxp201 & 3967.0 & 1.1 & $222.5^{*}$ & $2.9^{*}$ & $7303.0+$ & $1.9+$ & 256.0 & 1.0 \\
\hline Xtxp177 & $16480.0^{* *}$ & $4.9^{\star *}$ & $407.3^{\star *}$ & $5.3^{\star *}$ & 4659.0 & 1.2 & 293.4 & 1.1 \\
\hline Xtxp303 & 3714.0 & 1.1 & $284.5^{*}$ & $3.6^{*}$ & $10539.0+$ & $2.7+$ & $754.5^{\star}$ & $3.0^{*}$ \\
\hline Xtxp295 & 1740.0 & 0.5 & 69.0 & 0.8 & 2023.0 & 0.5 & $1383.4^{* *}$ & $5.7^{* \star}$ \\
\hline Xtxp95 & 35.0 & 0.1 & 4.6 & 0.1 & 6223.0 & 1.6 & $697.1+$ & $2.8^{+}$ \\
\hline
\end{tabular}

${ }^{+},{ }^{*},{ }^{* *},{ }^{* * *}=$ significantly different at $\mathrm{P}<0.1, P<0.05, P<0.01$ and $\mathrm{P}<0.001 . \mathrm{a}=$ Area under disease progress curve; $\mathrm{b}=$ Final severity was taken 40 days after inoculation

resistances are sensitive to genotype $\mathrm{x}$ environmental interactions (Mohan et al., 2010). Thus, consistent heavy disease pressure is required to accurately determine the magnitude of the genetic factor that contributes to these resistance.

Association of SSRs to anthracnose and TLB. Four SSRs had PIC higher than 0.5 and the rest of SSRs had a PIC between 0.44 and 0.48. Polymorphism of loci is considered high if values are greater than 0.5 or between $0.5-0.25$ (Abu Assar et al., 2005). Thus, nearly all of the SSRs used in this study, i.e. Xtxp302, Xtxp25, Xtxp201, Xtxp177, Xtxp303, Xtxp295 and Xtxp95, could provide substantial information for the genetics and breeding of sorghum. These SSRs multiple loci to diseases have been genetically mapped (Kong et al., 2000; Mohan et al., 2010). In this study we find that the SSRs Xtxp25 and Xtxp201 segregated in a manner consistent with two loci with epistasis and dominant for anthracnose and the SSRs Xtxp302, Xtxp25, Xtxp295 and Xtxp95 were associated with segregation of two loci (epistasis and dominant) for TLB. Interestingly, marker Xtxp95 had highly significant association between the allelic groups for anthracnose and TLB.

It has been suggested that SSR Xtxp95, among others in the sixth linkage group, could harbour a cluster of disease resistance to diverse fungal pathogens (Mohan et al., 2009). The same region is in synteny with linkage group four of rice and group two of maize linkage (Young, 1996). Thus, the information gained from this study and others, suggests that this is a highly conserved locus among gramineae essential for protection against especially fungal pathogen. These SSRs markers could provide additional tools for marker assisted breeding for anthracnose and TLB and map-based isolation of multiple disease resistant loci in sorghum.

Co-segregation of anthracnose and TLB resistant loci. SSR Xtxp25 exhibited dominant epistasis for resistance to anthracnose and TLB (Table 4). This SSR Xtxp25 was selected from linkage group two of sorghum that has been reported to have resistant loci for TLB in sorghum (Martin et al., 2011). In general, disease resistance loci cluster on different chromosomes as observed in other crops such as maize (Ali et al., 2013). Indeed, SSRs Xtxp25 and Xtxp201 for anthracnose and Xtxp302, Xtxp25, Xtxp295 and Xtxp95 for TLB were associated with dominant epistasis, and were distributed across sorghum genome with high PIC and gene diversity frequencies. Other studies show a high association for the same SSRs to resistance in maize, to the foliar diseases TLB, and grey leaf spot on maize (Paterson, 2008; Mace et al., 2009; Mohan et al., 2010; Ali and Yan, 2012). In maize, resistance QTL associated with TLB, grey leaf spot and southern leaf blight are randomly 
TABLE 4. Chi squares and segregation patterns of the seven polymorphic SSR loci among 126 RILs under Uganda and Sudan field conditions (rains of 2012 and 2014 )

\begin{tabular}{|c|c|c|c|c|c|c|c|c|c|}
\hline No. of loci & Segregation pattern & Segregation ratio & Xtxp302 & Xtxp25 & Xtxp201 & Xtxp177 & Xtxp303 & Xtxp295 & Xtxp95 \\
\hline \multicolumn{10}{|c|}{ Anthracnose (source of resistance was Epuripuri) } \\
\hline \multirow[t]{2}{*}{ One locus } & Dominant & $1 \mathrm{R}: 2 \mathrm{H}: 1 \mathrm{~S}$ & 48. $27^{\star * *}$ & $96.60^{\star \star *}$ & $16.14^{\star * *}$ & $97.87^{\star \star \star}$ & $61.81^{* * *}$ & $31.08^{\star * *}$ & $104.73^{\star * *}$ \\
\hline & Recessive & $1 \mathrm{~S}: 2 \mathrm{H}: 1 \mathrm{R}$ & $48.27^{\star \star \star}$ & $96.60^{\star \star *}$ & $16.14^{\star * *}$ & $97.87^{\star \star \star}$ & $61.81^{\star \star *}$ & $31.08^{\star \star *}$ & $104.73^{\star * *}$ \\
\hline \multirow[t]{4}{*}{ Two locus } & Dominantepistasis & 9R:7S & $13.06^{\star * *}$ & 1.52 & 1.05 & $14.83^{* * *}$ & $15.79^{\star \star *}$ & $3.99^{*}$ & $3.14^{*}$ \\
\hline & Dominantepistasis & $15 R: 1 S$ & $99.66^{\star \star \star}$ & $396.80^{* * *}$ & $229.79^{* * *}$ & $646.05^{\star \star *}$ & $85.50^{\star \star *}$ & $176.76^{\star \star *}$ & $442.01^{* * *}$ \\
\hline & Recessive epistasis & $9 \mathrm{R}: 4 \mathrm{H}: 3 \mathrm{R}$ & $6.79^{*}$ & $82.99^{* * *}$ & $51.69^{* * *}$ & $147.70^{\star * *}$ & $4.89^{*}$ & $23.73^{\star * *}$ & $96.66^{\star * *}$ \\
\hline & Recessive epistasis & $9 \mathrm{R}: 3 \mathrm{H}: 4 \mathrm{~S}$ & $74.97^{\star \star *}$ & $212.16^{\star * *}$ & $96.35^{\star * *}$ & $714.59^{* * *}$ & $77.77^{\star \star *}$ & $63.00^{* * *}$ & $288.78^{* * *}$ \\
\hline \multicolumn{10}{|c|}{ Turcicum leaf blight (source of resistance was MUC007/009) } \\
\hline \multirow[t]{2}{*}{ One locus } & Dominant & $1 \mathrm{R}: 2 \mathrm{H}: 1 \mathrm{~S}$ & $48.27^{\star * *}$ & $96.60^{* * *}$ & $16.14^{* * *}$ & $97.87^{\star \star \star}$ & $61.81^{* * *}$ & $31.08^{* * *}$ & $104.73^{* * *}$ \\
\hline & Recessive & $1 \mathrm{~S}: 2 \mathrm{H}: 1 \mathrm{R}$ & $48.27^{\star \star \star}$ & $96.60^{* * *}$ & $16.14^{* \star *}$ & $97.87^{\star \star *}$ & $61.81^{* \star *}$ & $31.08^{* * *}$ & $104.73^{* * *}$ \\
\hline \multirow[t]{4}{*}{ Two locus } & Dominant epistasis & 9R:7S & 1.52 & 0.02 & $15.18^{\star \star \star}$ & $17.91^{\star \star *}$ & $4.55^{\star}$ & 0.85 & 0.01 \\
\hline & Dominant epistasis & $15 R: 1 S$ & $396.80^{\star * \star}$ & $313.70^{\star \star *}$ & $85.94^{* * *}$ & $78.43^{\star \star \star}$ & $473.50^{\star \star \star}$ & $240.36^{\star \star \star}$ & $300.80^{\star \star *}$ \\
\hline & Recessive epistasis & $9 \mathrm{R}: 4 \mathrm{H}: 3 \mathrm{R}$ & $80.69^{* * *}$ & $63.01^{* * *}$ & $14.67^{\star \star \star}$ & $9.28^{* \star}$ & $100.84^{* * *}$ & $39.64^{* * *}$ & $62.80^{\star * *}$ \\
\hline & Recessive epistasis & $9 \mathrm{R}: 3 \mathrm{H}: 4 \mathrm{~S}$ & $200.84^{\star \star *}$ & $128.65^{\star \star *}$ & $66.39^{\star \star *}$ & $71.70^{\star \star \star}$ & $315.34^{* \star *}$ & $73.86^{\star \star *}$ & $127.95^{\star \star *}$ \\
\hline
\end{tabular}

$\mathrm{R}=$ resistant; $\mathrm{H}=$ heterozygote; $\mathrm{S}$ = susceptible 
distributed in the genome, but clustered at different regions of the chromosomes (Ali et al., 2013). Clustering of resistance loci, invariably can permit inheritance of such loci, and with molecular markers that co-segregate for these loci, their deployment in resistance breeding will pave way for more effective breeding schemes for both diseases in sorghum (Mohan et al., 2010).

\section{CONCLUSION}

The general shape of histograms and analysis of variance analysis confirmed resistance as qualitative for anthracnose and quantitative for TLB with resistance exhibiting dominance epistasis associated with SSR markers that cosegregate for resistance to both diseases. These SSRs, when coupled with phenotypic data, will improve screening for dual resistance and the development of novel sorghum. These SSRs markers could provide additional tools for marker assisted breeding for anthracnose and TLB and map-based isolation of multiple disease resistant loci in sorghum.

\section{ACKNOWLEDGEMENT}

The authors thank the German Academic Exchange Service (DAAD), through the Regional Universities Forum for Capacity Building in Agriculture (RUFORUM), for funding this research. Gratitude is due to the Biotechnology and Biosafety Research Centre in the Agricultural Research Corporation (ARC) in Sudan for hosting the laboratory work.

\section{REFERENCES}

Abu Assar, A.H., Uptmoor, R., Abdelmula, A.A., Salih, M., Ordon, F. and Fried, W. 2005. Genetic variation in sorghum germplasm from the Sudan, ICRISAT and USA assessed by simple sequence repeats. Crop Science 45:1636-1644.

Ali, F. and Yan, J.B. 2012. The phenomenon of disease resistance in maize and the role of molecular breeding in defending against global threat. Journal Integrated Plant Biology 55:134-151.
Ali, F., Pan, Q., Chen, G., Zahid, K.R. and Yan, J. 2013. Evidence of multiple disease resistance (MDR) and implication of meta-analysis in marker assisted selection. PLOS ONE 8(7):e68150. doi:10.1371/journal.pone. 0068150.

Beshir, M.M. 2011. Development of molecular markers for introgression of resistance to Turcicum leaf blight in sorghum. MSc. thesis. Makerere University, Kampala, Uganda. pp. 26-84.

Beshir, M.M., Ahmed, N.E., Ali, A.M., Babiker, I. H., Rubaihayo, P. and Okori, P. 2015. Prevalence and severity of sorghum leaf blight in the sorghum growing areas of central Sudan. Wudpecker Journal of Agricultural Research 4(6):54-60.

Costa, R.V., Zambolim, L., Cota, L.V., Silva, D.D., Rodrigues, J.A.S., Tardina, F.D. and Casela, C.R. 2011. Genetic control of sorghum resistance to leaf anthracnose. Plant Pathology 60:1162-1168.

Edwards, K., Johnstone, C. and Thompson, C. 1991. A simple and rapid method for the preparation of plant genomic DNA for PCR analysis. Nucleic Acid Research 19:13-49.

FAOSTAT. 2011. Food and Agriculture Organization of the United Nations, Statistics Division online available at http:// faostat3.fao.org

Geiger, H.H. and Heun, M. 1989. Genetics of quantitative resistance to fungal diseases. Annual Review Phytopathology 27:317-341.

Kong, L., Dong, J. and Hart, G.E. 2000. Characteristics, linkage-map positions, and allelic differentiation of Sorghum bicolour (L.) Moench DNA simple-sequence repeats (SSRs). Theoretical and Applied Genetics 101:438-448.

Mace, E.S., Rami, J.F., Bouchet, S., Klein, P.E., Klein, R.R., Kilian, A., Wenzl, P., Xia, L., Halloran, K. and Jordan, D.R. 2009. A consensus genetic map of sorghum that integrates multiple component maps and highthroughput Diversity Array Technology (DArT) markers. BioMed Central Plant Biology 9:13.

Madden, L.V., Hughes, G. and van den Bosch, F. 2007. The study of plant disease epidemics. 
American Phytopathological Society. St. Paul Minnesota, USA.

Martin, T., Biruma, M., Fridborg, I., Okori, P. and Dixelius, C. 2011. A highly conserved NBLRR encoding gene cluster effective against Setosphaeria turcica in sorghum. BioMed Central Biology 11:151.

McDonald, B.A. and Linde, C. 2002. Pathogen population genetics, evolutionary potential and durable resistance. Annual Review of Phytopathology 40:349-379.

Mittal, M. and Boora, K.S. 2005. Molecular tagging of gene conferring leaf blight resistance using microsatellites in sorghum (Sorghum bicolour (L.) Moench). Indian Journal of Experimental Biology 43(5):462466.

Mohan, S.M., Madhusudhana, R., Mathur, K., Howarth, C.J., Srinivas, G., Satish, K., Reddy, R.N. and Seetharama, N. 2010. Identification of quantitative trait loci associated with resistance to foliar diseases in sorghum (Sorghum bicolor (L.) Moench). Euphytica 176:199-211.

Mohan, S.M., Madhusudhana, R., Mathur, K., Howarth, C.J., Srinivas, G., Satish, K., Reddy, R.N. and Seetharama, N. 2009. Co-localization of quantitative trait loci for foliar disease resistance in sorghum. Plant Breeding 128:532-535.

Ngugi, H.K., Julian, A.M., King, S.B. and Peacocke, B.J. 2000. Epidemiology of sorghum anthracnose (Colletotrichum sublineolum) and leaf blight (Exserohilum turcicum) in Kenya. Plant Pathology 49:129.

Okori, P., Rubaihayo, P.R., Adipala, E. Fahieson, J. and Dixelius, C. 2015. Dynamics of Cercospora zeina populations in maize-based agro-ecologies of Uganda. African Crop Science Journal 23:45-57.

Paterson, A.H. 2008. Genomics of sorghum. International Journal of Plant Genomics ID 36245. Doi:10.1155/2008/362451.

Rajeshwar, R.P., Narayan, P.R. and Ranga, R.R. 2014. Turcicum leaf blight of maize incited by Exserohilum turcicum: A review. International Journal of Applied Biology and Pharmaceutical Technology 5(1):54-59.

Ramathani, I. 2009. Characterisation of Turcicum leaf blight epidemics and pathogen populations in the Exserohilum turcicum Sorghum pathosystem in Uganda. MSc thesis. Makerere University, Kampala, Uganda. pp. 22-95.

Ramathani, I., Biruma, M., Martin, T., Dixelius, C. and Okori, P. 2011. Disease severity, incidence and races of Setosphaeria turcica on sorghum in Uganda. European Journal of Plant Pathology 131(3):383-392.

Sharma, H.C., Dhillon, M., Pampapathy, G. and Reddy, B. 2007. Inheritance of resistance to spotted stem borer (Chilopartellus) in sorghum, Sorghum bicolour. Euphytica 156:117-128.

Steel, R.G.D. and Torrie, J.H. 1997. Principles and Procedures of Statistics: A biometrical approach. McGraw-Hill, New York, USA.

Sserumaga, J.P., Biruma, M., Akwero, A., Okori, P. and Edema, R. 2013. Genetic characterisation of Ugandan strains of Colletotrichum sublineolum using ISSR makers. Uganda Journal of Agricultural Sciences 14:111-123.

Tesso, T., Perumal, R., Little, C.R., Adeyanju, A., Radwan, G., Prom, L. and Magill, C. 2012. Sorghum pathology and biotechnology - A fungal disease perspective: Part 2 . Anthracnose, Stalk Rot and Downy Mildew. The European Journal of Plant Science and Biotechnology 6(1):31-44.

Vanderlip, R.L. 1993. How a sorghum plant develops. Cooperative extension service. Manhattan, Kansas: Kansas Agricultural Experiment Station 1203, Kansas, USA.

Varshney, R.K. Pandey, MK., Janila, P., Nigam, S.N., Sudini, H.K., Gowda, M.V.C., Manda Sr iswathi, T. Radhakrishnan, Manohar, S.S. and Nagesh, P. 2014. Marker-assisted introgression of a QTL region to improve rust resistance in three elite and popular varieties of peanut (Arachis hypogaea L.). Theoretical and Applied Genetics doi:10.1007/s00122014-2338-3.

Weltz, H.G. 1998. Genetics and epidemiology of the pathosystem Zea mays/Setosphaeria turcica. Doctoral thesis. University of Hohenheim, Stuttgart, Germany.

Young, N.D. 1996. QTL mapping and quantitative disease resistance in plants. Annual Review Phytopathology 34:479-501. 